\title{
The Evolution of Social Capability and Economic Resilience: A Case Study of Yunnan Province
}

\author{
Sujun $\mathrm{Shao}^{1, *}$ \\ ${ }^{1}$ School of Development Studies, Yunnan University, Kunming, Yunnan, China \\ "Corresponding author. Email: 25836338@qq.com

\begin{abstract}
Economic development may encounter unexpected shocks, such as financial crises, major epidemics and natural disasters. The ability of a country's economy to recover from such shocks determines its long-term economic development trend. This article combines the theory of economic resilience and the theory of social capabilities to construct an analysis framework of economic resilience based on social capabilities. From the two dimensions of resistance and recoverability, it establishes the conceptual framework and conceptual framework of economic resilience for 16 prefecture-level cities in Yunnan Province from 2005 to 2017. The indicator system analyzes the evolutionary stages of economic resilience in Yunnan Province, and then analyzes the countermeasures for the economic transformation of Yunnan Province based on social capabilities.
\end{abstract}

\section{Keywords: social capability, economic resilience, Yunnan Province}

\section{INTRODUCTION}

The concept of resilience was originally proposed in engineering and ecology to study the ability of a system to recover to its original state after being disturbed or shocked (Martin, 2012; Reggiani, 2013). Holling (1973) first introduced the concept of resilience in ecology, using resilience to describe the ability of ecosystems to survive under disturbance or adverse conditions. Later, many other disciplines introduced the concept of resilience. The concept of resilience in different disciplines has undergone many changes. Most notably, both engineering resilience and ecological resilience assume equilibrium and stability in the system (Holling, 1973; Martin and Sunley, 2015). However, many systems do not have equilibrium, so the concept of adaptability is applied to resilience and developed into adaptive resilience (Martin, 2012; Boschma, 2015). Adaptive resilience refers to the ability of a system to change, adapt and transform in response to external pressures in the long-term evolution process (Boschma, 2015). The adaptive resilience view holds that even in the absence of shocks, the continued demand for economic growth and change will prevent economic stagnation or recession, rather than simply interpreting resilience as a return to an existing stable equilibrium. Therefore, economic resilience should include the following three aspects: (1) the long-term ability of a country or region to develop new industries or new technologies to achieve new growth paths; (2) the ability to withstand shortterm shocks and economic recovery; and (3) the ability to respond to short-term shocks to achieve new long- term growth paths (Carpenter et al., 2005; Simmie and Martin, 2010; Boschma, 2015).

As a conceptual tool, economic resilience can be used to answer a long-standing question: why some economies can self-renew and achieve long-term growth, while some economies continue to fall into recession (Hassink, 2010). Economic resilience is used to measure the ability of an economy to respond to shocks, including global economic crises, natural disasters, and major epidemics, etc. (Martin, 2012; Davoudi et al., 2013; Boschma, 2015). Frequent external shocks have profoundly affected the economic development of a country or region. Some regions actively responded to the shocks and restored their development paths, while other regions fell into recession under the shocks (Simmie and Martin, 2010; Doran and Fingerton, 2016).

Based on theoretical development, the empirical research has also analyzed various factors that affect economic resilience. A diversified industrial structure, skilled and innovative workforce, modern infrastructure, supportive financial system, free market conditions, knowledge networks between scientific research institutions and local economies, and active government development strategies have all enhanced the economic resilience of a country or region (Christopherson et al., 2010; Martin; 2012; Boschma, 2015; Di Caro, 2015).

However, few studies have attempted to study economic resilience from the perspective of capabilities, especially social capabilities. Social 
capability is a strong, continuous and direct determinant of economic growth (Louis Putterman, 2013). From a historical perspective, the transformation from an agricultural society to an industrial society to the current information society shows that the density and use of investment capital, human capital, and social capital are constantly increasing. What a society can handle these changes is their constantly accumulated social capability. For catching-up countries, catchingup depends not so much on capital accumulation as it depends on a country's ability to create and use knowledge. The ability of countries to produce and disseminate scientific and technological knowledge, that is, the ability to use knowledge (social capability), is the basis of sustainable economic growth and catching up (UNIDO, 2005). Therefore, this research is based on the theory of economic resilience and social capability, and establishes an analysis framework of economic resilience based on social capability from the two dimensions of resistance and recoverability. At the same time, taking 16 prefecture-level cities in Yunnan from 2005 to 2017 as the research objects, an analysis framework and a comprehensive indicator system reflecting the changes in Yunnan's economic resilience were constructed, and the economic resilience of Yunnan Province was analyzed from the two dimensions of resistance and recoverability, in order to identify the characteristics of Yunnan's economic resilience, and provide countermeasures and suggestions for the economic transformation of Yunnan Province.

\section{MATERIALS AND METHODS}

\section{A. Study area}

There are 16 prefecture-level units in Yunnan Province, including 8 prefecture-level cities and 8 states. Yunnan is rich in mineral resources. 142 kinds of mineral resources have been discovered, 92 kinds of mineral resources have proven reserves, and the reserves of 61 kinds of mineral resources rank among the top 10 in China. Non-ferrous metals are Yunnan's biggest mineral advantage. Among them, the reserves of 9 minerals such as aluminum, zinc, tin, and phosphorus rank first in China, and the total reserves of 12 minerals including platinum, germanium, diatomite, copper, antimony, and nickel rank nationally Top 3; copper and nickel reserves rank the third in China. Among the ferrous metal minerals, Yunnan has five kinds of iron, manganese, titanium, chromium, and vanadium. Among them, the reserves of titanium placer ore rank 4th in China, and the reserves of iron and manganese rank 6th (among which the reserve of rich iron ore occupies the first place in China). Among the precious metals and rare element minerals, the reserves of indium, thallium, and cadmium rank first in China, and the reserves of silver, germanium and platinum group metals rank second in China. Other mineral resources are also extremely rich. Among the chemical raw materials, phosphorus, salt, mirabilite, arsenic, potash, pyrite, limestone for calcium carbide, and serpentine for fertilizers have a total of 8 mineral reserves, ranking the top 10 in China. These mineral resources are distributed in 16 prefecture-level cities, each of which has advantageous mineral resources. Although Yunnan Province was included in the 2013 "National Resource-Based Cities List", only Qujing City, Baoshan City, Zhaotong City, Lijiang City, Pu'er City, Lincang City and Chuxiong Yi Autonomous Prefecture 7 prefecture-level units, but most of Yunnan's prefecture industry development shows resource dependence, so this study included 16 prefecture-level units in Yunnan.

Yunnan province is rich in natural resources, which leads to the over-dependence of economic growth on natural resources. Due to excessive resource dependence and inefficient use, the regional development of Yunnan has increased the pressure on the natural environment, and the development sustainability is weak. At present, the five pillar industries in Yunnan are tobacco industry, biological resource development and innovation industry with food as the focus, mineral industry with phosphorus chemical industry and non-ferrous metal as the focus, tourism with natural scenery and ethnic customs as the characteristics, and electric power industry with hydropower as the main part, which are basically resource-based industries. Therefore, although Yunnan industry has established a basically complete industrial system, the overall level of industrialization is relatively low. The main performance is: the industrial structure level is low, the traditional industry, resources industry than major, manufacturing industry and high-tech industry development lags behind, the industrial structure of resource-based and weak long-term failed to break through the pattern of the pillar industries; Due to the low degree of industrial correlation within the industry, it is difficult to deepen and refine the industrial chain. Most of the industrial industries are small in scale and weak in competitiveness, and there are few advantageous industries with national significance.

\section{B. Economic resilience analysis framework and indicator system}

1) Economic resilience analysis framework based on social capabilities: In essence, the social capabilities include a variety of institutional and human resources that enable some countries to develop faster than others (Dwight H. Perkins and Bon Ho Koo, 1995). The term "social capability " was originally proposed by Ohkawa and Rosovsky (1973) in the study of Japan's growth miracle, as an explanation for its effective utilization of imported advanced technology, and was later derived to 
refer to the social characteristics that prevent a backward country from achieving a comprehensive technological leap. However, the discussion of social capabilities can be traced back to the theory of "latemover advantage", that is, how late-mover countries can effectively realize "late-mover advantage" to promote economic growth. Gerschenkron (1962) pointed out that some countries are at the forefront of technology, while other countries are relatively backward in technology. Although the technological gap between the two means that backward countries have "great hope" and can achieve rapid growth by imitating cutting-edge technologies, there are also many problems that hinder backward countries from obtaining maximum profits. Therefore, backward countries need to invent new institutional tools to overcome these obstacles, state intervention is necessary to make up for these shortcomings. So what he really focused on was the capabilities needed to catch up and the role of public and private participants in developing these capabilities, which came to be known as "social capabilities ".

Abramovitz's discussion of social capabilities originated from the complement and improvement of catch-up theory. When analyzing the history of economic catch-up, Abramovitz (1986) found that technological consistency and social capabilities together determine the possibility of a country's catching-up. Technological consistency refers to the degree of consistency between the leader and the catching-up country in terms of market size and factor supply, etc. Social capabilities refer to the capabilities that developing countries must develop in order to catch up, including the organization and management experience of large enterprises, education and business infrastructure. In the first half of the post-World War II period, Western Europe succeeded in catching up with the United States, not only because of the improvement of technological consistency, but also the improvement of social capabilities. Therefore, a country's potential for rapid growth is strong, not when it falls behind unconditionally, but when it is technologically backward but socially capabilities forward.

Laggard countries are easily inconsistent with the technical and organizational arrangements required by developed countries in terms of resource availability, factor supply, technological capabilities, market size, and consumer demand, and the evolution of the technological and organizational systems of backward countries have path dependence, it is difficult to quickly transform from an established system and its related technological development track to a rather unique technological system that has emerged elsewhere under different economic and social conditions. Technological backwardness and the various economic characteristics that hinder countries from overcoming technological backwardness are not just accidental phenomena. Behind them lies a tenacious social characteristic, which is called "social capability". It is this capability that determines whether a country could acquire, adjust and internalize the existing technology and management knowledge of developed countries. The speed at which a country acquires, absorbs and uses advanced technology and its ability to sustain this process in the long term will determine its long-term growth performance. As a tenacious social characteristic, social capability is one of the reasons why a country cannot achieve the high level of productivity of a more economically advanced country, preventing backward countries from achieving the full technological leap envisaged by the catch-up theory. Therefore, technological consistency and social capabilities are interrelated, and technological consistency is dominated by social capabilities to a certain extent. One of the reasons that hinder countries from overcoming technological backwardness is the backwardness of national social capabilities.

In the long-term economic growth process, there will always be shocks from economic cycle fluctuations, policy adjustments, financial crises, technological innovations, etc. These shocks may cause a country's economy into trouble. Some countries are not only less affected by the shock, but can quickly return to the growth track after the shock. Some countries are not only heavily affected by the shock, but also gradually decline due to the lack of capability to cope with the shock. Therefore, different countries have different economic resilience. Judging from the history of economic catch-up, late-developing countries do not lack rapid growth in a certain period, but it is difficult to maintain long-term growth. After World War II, many countries have already crossed the threshold of middle-income countries, but decades later, these countries have experienced serious differentiation: on the one hand, Latin American countries represented by Brazil and Argentina have been hovering at the middleincome level for a long time. The economy lacks resilience and growth has fallen into a "trap"; on the other hand, a few countries represented by Japan and South Korea have achieved sustained growth and their economies have shown strong resilience. They have successfully overcome the "trap" and joining the ranks of high-income countries.

Martin Andersson (2018), based on the analysis of social capabilities by Abramovitz (1986), believes that the five interconnected social capabilities have special significance for economic resilience. By strengthening these social capabilities, a country's economic resilience can be enhanced, thereby better promoting the long-term development of a country's economy. Since the 1950s, Asia has made considerable progress compared to other developing regions, not only because 
it has grown more economically, but also because its economy has shrunk less, that is, the economy is more resilient, and the Asian economy is more resilient due to its stronger social capabilities.

Martin Andersson (2018) incorporated social capabilities into the analysis of economic resilience, well linked social capabilities with economic resilience, and opened a new way of analyzing economic resilience. But regarding the influencing factors of social capability, academic circles have different understandings. As Abramovitz (1986) emphasized, as a trait, social capability is cumulative, localized, and national. Therefore, social capability is difficult to define and accurately measure. Abramovitz (1986) believes that the following aspects are particularly important to social capabilities: (1) technical capabilities (education level); (2) organization and management experience of large enterprises; (3) financial institutions and markets that can mobilize funds on a large scale; (4) Honesty and trust; (5) A stable government and its effectiveness in formulating and implementing rules and maintaining economic growth. Fagerberg and Srholec (2005) based on Abramovitz's research, by summarizing and evaluating different methods in the social capabilities literature, they identified five indicators that reflect different aspects of social capabilities: (1) human capital; (2) the degree of openness across borders; (3) The degree of technology diffusion; (4) The resource mobilization capacity of the financial system; (5) The efficiency of the financial system. Based on the above-mentioned capability indicators, an empirical analysis of 135 countries in the 1990s has been carried out, and it is found that social capabilities represented by knowledge and the efficiency of the financial system are essential for catching up. Jens Andersson and Martin Andersson (2019), by measuring and discussing the key elements of social capabilities in Côte d'Ivoire and Senegal from 1930 to 1980 , summarized four factors affecting social capabilities: (1) the degree of structural transformation; (2) society and economy Inclusiveness; (3) Financial equity; (4) Governance efficiency. From this, it can be found that different scholars have selected different indicators based on the needs of analysis in the process of research, but the relevant indicators have similarities, and they all reflect social capability as the basic feature that affects long-term economic growth.

Therefore, based on Abramovitz's (1986, 1995) classic discourse and subsequent scholars' related discourses, especially Martin Andersson (2018, 2019) related research, this article summarizes the important influence factors of social capability into the following four aspects: (1) inclusiveness of growth; (2) flexibility of industrial structure; (3) social trust; (4) effectiveness of governance.
In the process of economic development, different types of shocks affect a country's economic development in different ways. Economic resilience refers to the ability of an economy to mitigate the impact of shocks and quickly restore its original development path or turn to a better development path (Martin, 2012; Martin and Sunley, 2015). Therefore, economic resilience includes two dimensions: resistance and recoverability. Resistance mainly refers to the economic system's ability to resist shocks or disturbances. This depends on the possibility of unexpected shocks and the resistance of the region to such unexpected shocks, which are generally determined by regional structural characteristics, economic openness, working conditions, infrastructure and policy systems. Recoverability mainly reflects the ability of a regional economic system to restore its development path or realize a new development path by adjusting its structure and organization. Recoverability is determined by the degree of adaptation and the ability to learn and transform, and is mainly affected by the regional economic structure, policy support, foreign capital utilization, technological innovation capabilities and financial environment.

2) Index system composition: Based on the conceptual model of economic resilience and the above-mentioned related research, and considering the availability and comparability of data, this paper constructs an economic resilience index system based on social capabilities containing 30 indicators. Each level of economic resilience (i.e., resistance and recoverability) is divided into four dimensions, and each dimension is composed of different indicators of social capabilities ("Table I"). 
TABLE I. INDICATOR SYSTEM OF ECONOMIC RESILIENCE

\begin{tabular}{|c|c|c|c|c|}
\hline $\begin{array}{l}\text { First-level } \\
\text { index }\end{array}$ & $\begin{array}{c}\text { Second-level } \\
\text { index }\end{array}$ & $\begin{array}{l}\text { Third-level } \\
\text { index }\end{array}$ & Fourth-level index & No. \\
\hline \multirow{30}{*}{$\begin{array}{l}\text { Economic } \\
\text { Resilience }\end{array}$} & \multirow[t]{15}{*}{ Resistance } & \multirow{3}{*}{$\begin{array}{l}\text { flexibility } \\
\text { industrial } \\
\text { structure }\end{array}$} & Percentage of secondary industry in GDP $(\%)$ & 1 \\
\hline & & & Number of legal entities & 2 \\
\hline & & & The ratio of urban employees to rural employees $(\%)$ & 3 \\
\hline & & \multirow{4}{*}{$\begin{array}{l}\text { inclusiveness of } \\
\text { growth }\end{array}$} & GDP per capita & 4 \\
\hline & & & Proportion of health and social workers $(\%)$ & 5 \\
\hline & & & The population density & 6 \\
\hline & & & The total wages of employees as a percentage of GDP $(\%)$ & 7 \\
\hline & & \multirow[t]{4}{*}{ social trust } & $\begin{array}{l}\text { Proportion of employees in power, heat, gas and water } \\
\text { production and supply industries }(\%)\end{array}$ & 8 \\
\hline & & & The ratio of total import and export to GDP $(\%)$ & 9 \\
\hline & & & Urban population as a percentage of total population (\%) & 10 \\
\hline & & & $\begin{array}{l}\text { Proportion of staff in public administration, social security and } \\
\text { social organizations }(\%)\end{array}$ & 11 \\
\hline & & \multirow[t]{4}{*}{$\begin{array}{l}\text { effectiveness of } \\
\text { governance }\end{array}$} & $\begin{array}{l}\text { Proportion of employees in state-owned and collective units ( } \\
\%)\end{array}$ & 12 \\
\hline & & & Proportion of urban employees $(\%)$ & 13 \\
\hline & & & Public budget expenditure as a percentage of GDP (\%) & 14 \\
\hline & & & The ratio of financial institution loan balance to GDP (\%) & 15 \\
\hline & \multirow[t]{15}{*}{ Recoverability } & \multirow{4}{*}{$\begin{array}{l}\text { flexibility of } \\
\text { industrial } \\
\text { structure }\end{array}$} & The ratio of tertiary industry to GDP (\%) & 16 \\
\hline & & & $\begin{array}{l}\text { Total retail sales of consumer goods as a percentage of GDP ( } \\
\%)\end{array}$ & 17 \\
\hline & & & $\begin{array}{l}\text { The ratio of private and self-employed persons to total } \\
\text { employed persons }(\%)\end{array}$ & 18 \\
\hline & & & $\begin{array}{l}\text { Total number of inventions and patents granted at the end of } \\
\text { the year }\end{array}$ & 19 \\
\hline & & \multirow[t]{4}{*}{$\begin{array}{l}\text { inclusiveness of } \\
\text { growth }\end{array}$} & $\begin{array}{l}\text { Number of scientific and technical personnel in natural science } \\
\text { institutions }\end{array}$ & 20 \\
\hline & & & $\begin{array}{l}\text { Proportion of personnel in scientific research and technical } \\
\text { services }(\%)\end{array}$ & 21 \\
\hline & & & Education staff ratio $(\%)$ & 22 \\
\hline & & & Average salary of employees & 23 \\
\hline & & \multirow[t]{3}{*}{ social trust } & $\begin{array}{l}\text { Proportion of employees in information transmission, software } \\
\text { and information technology service industries }(\%)\end{array}$ & 24 \\
\hline & & & Ratio of rural population to total population $(\%)$ & 25 \\
\hline & & & Actual utilization of foreign investment & 26 \\
\hline & & \multirow{4}{*}{$\begin{array}{l}\text { effectiveness of } \\
\text { governance }\end{array}$} & City Innovation Index & 27 \\
\hline & & & Public budget revenue as a percentage of GDP (\%) & 28 \\
\hline & & & $\begin{array}{l}\text { The ratio of deposit balance of financial institutions to GDP ( } \\
\% \text { ) }\end{array}$ & 29 \\
\hline & & & $\begin{array}{l}\text { Comprehensive utilization rate of general industrial solid } \\
\text { waste }(\%)\end{array}$ & 30 \\
\hline
\end{tabular}

Since the "Bridgehead" strategy implemented in 2009 and the "One Belt, One Road" initiative implemented in 2013 are of great significance to Yunnan and also affect Yunnan's economic resilience, the study period was determined to be from 2005 to 2017. The statistical data mainly come from "The Statistical Yearbook of Chinese Cities " (National Bureau of Statistics, 2006-2018) and " The Statistical Yearbook of Yunnan Province " (Yunnan Bureau of Statistics, 2006-2018).

3) Research methods: There are many research methods for economic resilience. According to the different weights, it can be divided into subjective weighting method and objective weighting method. In order to scientifically reflect the economic resilience of the 16 prefecture-level cities in Yunnan, this paper adopts the entropy method for objective weighting, and the weight is determined by information entropy. In order to realize the comparison between different years, this article adds a time variable to improve the entropy method. The details are as follows:

- Index selection: Set $t$ years, $n$ prefecture-level cities, and $m$ indexes, then $\boldsymbol{X}_{\theta i j}$ is the $j$ th index value of city $i$ in year $\theta$. 
- Standardization of indicators: Standardization can help eliminate the different dimensions and units between indicators. Positive standardization: $x_{\theta i j}^{\prime}=\left(x_{\theta i j}-x_{\min }\right) /\left(x_{\max }-x_{\min }\right)$,

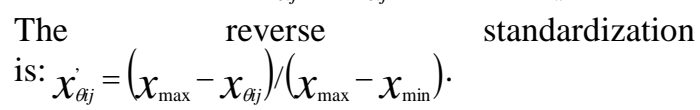

- Determine the index weight: $y_{\theta i j}=x_{\theta i j}^{\prime} / \sum_{\theta} \sum_{i} x_{\theta i j}^{\prime}$

- Calculate the entropy value of the $j$ th index: $e_{j}=-k \sum_{e} \sum_{i} y_{i j} \ln \left(y_{\theta_{i j}}\right), \quad$ while, $k>0$ $k=\ln (r n)$

- Calculate the information utility of the $j$ th index: $g_{j}=1-e_{j}$

- Calculate the weight: ${ }_{w_{j}}=1-\sum g_{j}$
- Calculate the resistance (recoverability) of each city:

$$
V R_{\theta j}\left(A T_{\theta j}\right)=\sum_{j}\left(w_{j} x_{\theta j}\right)
$$

- $V R_{\theta j}\left(A T_{\theta j}\right)$ is the resistance (recoverability) of the $i$ th city. This article believes that VR and AT have the same impact on economic resilience, so the economic resilience (RER) formula is as follows: $R$

$$
R E R_{\theta j}=V R_{\theta j}+A T_{\theta j}
$$

\section{RESULTS}

\section{A. Economic resilience of Yunnan Province}

"Fig. 1" shows the economic resilience, resistance and recoverability of the 16 prefecture-level cities in Yunnan Province, and shows the evolutionary characteristics of Yunnan's economic resilience in stages.

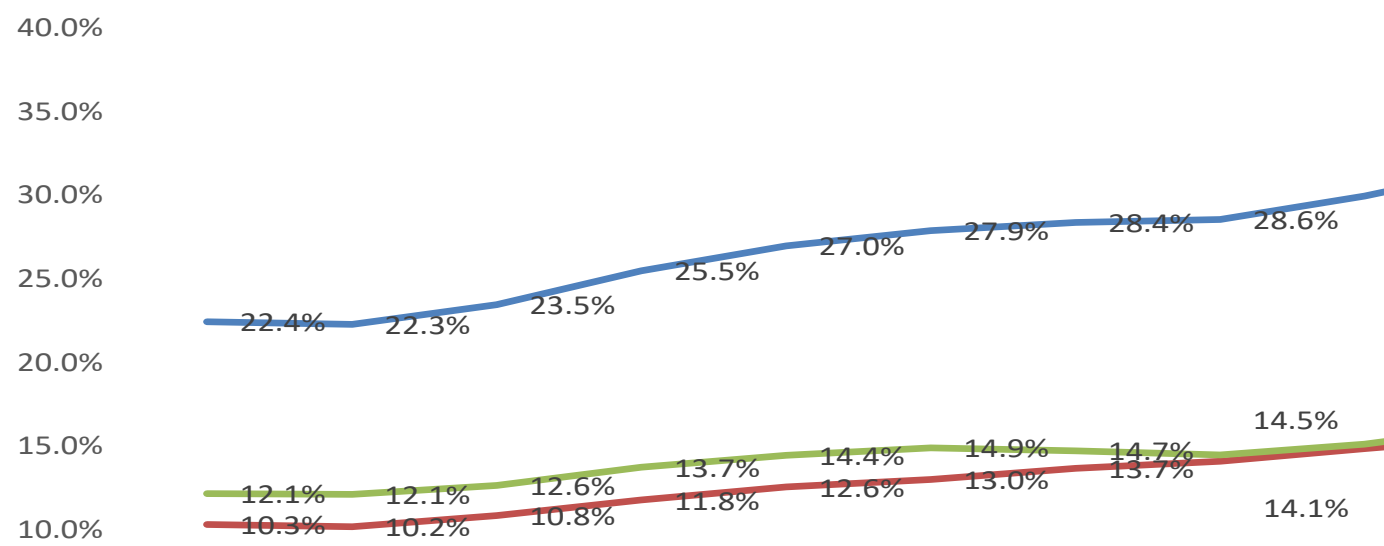

Fig. 1. Economic resilience (RER), resistance (VR) and recoverability (AT) of 16 prefecture-level cities in Yunnan Province.

From 2005 to 2017, the economic resilience of Yunnan Province has been on the rise. The value has risen from $22.4 \%$ in 2005 to $34.8 \%$ in 2017 , an increase of $12.4 \%$ in 12 years. From 2005 to 2006 , the economic resilience of Yunnan Province showed a short-term correction. From September 2005 to 2006, Yunnan Province rectified and regulated the development order of mineral resources. It shut down many small enterprises that had no license for mining. The economy of the prefectures-level cities has caused a certain impact. However, with the completion of rectification and regulation, a better and sustained economic growth has been achieved. The resources released by the region are reused, and the original path dependence is broken, which provides the possibility for the restoration and development of the region. Therefore, economic resilience also enters the upward channel. From 2007 to 2012, with the in-depth implementation of the Western Development Strategy and Yunnan's deepening of the rectification of mining resources, the economy of Yunnan Province has entered a stage of accelerated development. The pace of structural adjustment and reform of state-owned enterprises has accelerated, and the economy has recovered and grown rapidly. Yunnan Province has entered a stage of restructuring and development. Reusing resources through reorganization activities promoted technological innovation and new development paths. As a result, economic resilience improved rapidly, especially with 2012 as the watershed. In January 2013, the Yunnan Provincial Development and Reform Commission officially issued the "Master Plan for Yunnan Province to Accelerate the Construction of an Important Bridgehead for Southwest China opening (2012-2020)", starting from 2013, the economic resilience of Yunnan Province is showing a 
rapid rise. At the same time, the Belt and Road Initiative proposed by China in 2013 has injected new vitality into the development of Yunnan. As an important passage of the ancient Southern Silk Road, Yunnan has the unique geographical advantage of facing three parts of Asia and shouldering two oceans. It connects with the Silk Road Economic Belt in the north and the Maritime Silk Road in the south. It is the only province in China that can connect to South Asia and Southeast Asia from land, and connect Europe and Africa through the Middle East, with unique location advantages in the construction of the One Belt and One Road. With the adjustment and implementation of the One Belt and One Road Initiative in 2014, results have been shown since 2015. Although China's economy has entered the "new normal" stage of medium-to-highspeed growth, the economy of Yunnan Province still maintains a strong momentum for development and therefore economic resilience is still on the rise.

Looking at the evolution of resistance and recoverability, we can see that the resistance and recoverability also appeared similar trends from 2005 to 2012. There was a brief correction in 2006, and then resilience gradually increased steadily, even under the impact of the 2008 financial crisis, the resilience also increased. However, resistance declined in 2012, leading to a decline in the overall level of economic resilience in 2012. 2012 was the first year of the implementation of the bridgehead strategy, which imposed new requirements on the transformation of enterprises. Chemical commodities have entered a downward cycle. Iron and steel, coal and other black industries have ushered in massive overcapacity and low prices, which dragged down the profits of the corresponding industries, it also had a certain impact on the resource-based industries in Yunnan. With the same period of the European debt crisis, impact on the economy also caused a superposition of Yunnan province. However, with the further implementation of bridgehead strategy, especially the One Belt and One Road initiative put forward in 2013, the resistance and recoverability of Yunnan province have been rapidly increased, and the regional adjustment and transformation development of Yunnan province has been promoted.

It can also be seen that during this observation period, the recoverability of Yunnan Province is still lower than its resistance. Recoverability represents Yunnan's adaptability and innovation level; that is to say, when the external environment changes, the transformation and development of the regional economy can be achieved through adjustment and upgrading, or through the creation of new development paths. Yunnan's relatively low level of recoverability means that it cannot quickly adapt to environmental changes when shocks occur.

\section{B. Evolution characteristics of Yunnan's economic resilience}

In order to fully reflect the evolutionary characteristics of economic resilience of 16 prefecturelevel cities in Yunnan Province, the resistance and recoverability of 16 cities in Yunnan Province from 2005 to 2017 were analyzed.

1) Evolution characteristics of resistance: "Fig. 2" compares the resistance index of each city minus the average value of Yunnan Province. There are significant differences in the resistance of different cities.



Fig. 2. The resistance of 16 cities in Yunnan Province from 2005 to 2017. 
From 2005 to 2017, the resistance level of most cities was still lower than the average level of Yunnan Province. In general, only Kunming, Dehong and Diqing prefectures were higher than the average level of the province, indicating that these three cities had higher resistance in the face of internal and external shocks. Qujing, Zhaotong, and Yuxi have been below the average level of the province. Most of these cities are resource-based cities, and the secondary industry accounts for a relatively high proportion. In 2017, Qujing, Zhaotong and Yuxi's secondary industries accounted for $38 \%-51 \%$. Among them, the proportion of urban employees in Zhaotong is only $12 \%$, and the proportion of state-owned and collective-owned enterprises accounted for $71 \%$, resulting in insufficient regional economic vitality. The total import and export volume accounted for a very low proportion of GDP and lacked international competitiveness. As a result, the resistance of these cities is relatively low. In general, most cities in Yunnan Province are vulnerable to disturbance. Therefore, urban economic development is vulnerable to internal and external shocks, leading to regional economic recession. At the same time, the city's resistance to shocks is obviously differentiated.

2) Evolutionary characteristics of recoverability: "Fig. 3" compares the results of the city's recoverability index minus the average value of Yunnan Province. There are also significant differences in recoverability in different cities.

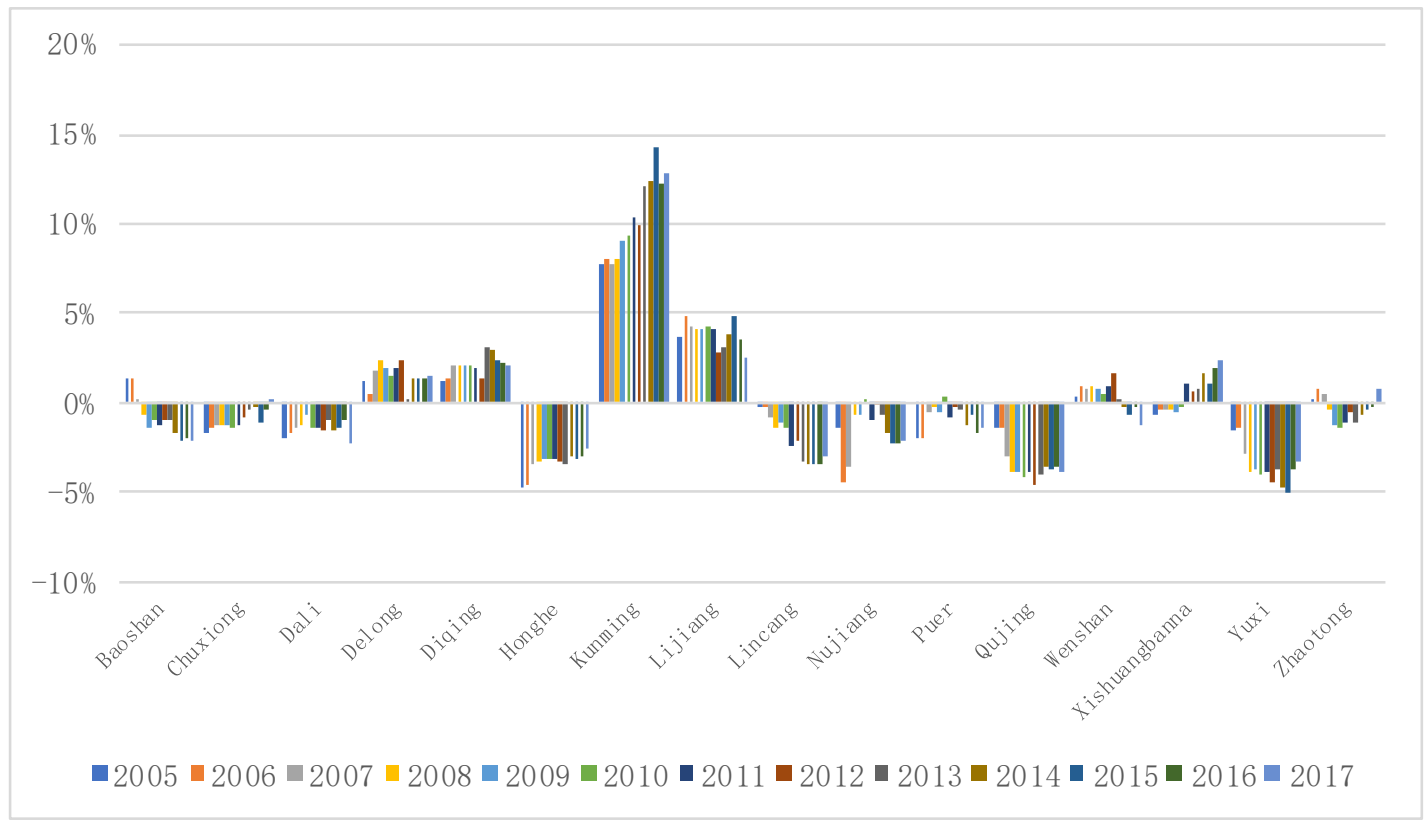

Fig. 3. The recoverability of 16 cities in Yunnan Province from 2005 to 2017.

From 2005 to 2017, the recoverability level of most cities was still lower than the average level of Yunnan Province. Overall, only Kunming, Lijiang, Diqing and Dehong were above the average level of the province, indicating that compared with other cities, these four cities can quickly adapt to the new environment and recover from the shock. The tertiary industry accounts for a relatively high proportion of GDP in these four cities. Except for the tertiary industry in Lijiang, which accounts for $44 \%$, the tertiary industry in the other three cities accounts for more than $52 \%$. As the core city of Yunnan Province, Kunming has a high degree of resource concentration and can quickly adjust the industrial structure. The proportion of the tertiary industry continues to rise and remains higher than other cities. Yuxi, Qujing and Honghe have been lower than the provincial average level, among which the tertiary industry in Yuxi, Qujing and Honghe accounted for 38$42 \%$. Most cities have a low ratio of researchers to the total population, a low index of urban innovation, and low investment in innovation activities, which limits innovation and transformation in these cities. The development path dependence of the secondary industry in Yunnan is significant, while the development of the tertiary industry is neglected. At the same time, resource-dependent traditional industries are more vulnerable to shocks, which restricts the transformation and development of regional economy. In general, cities in Yunnan Province have relatively weak recoverability after the shock.

3) Evolutionary characteristics of economic resilience: "Fig. 4" compares the economic resilience of each city minus the average value of Yunnan Province. 
Different cities have significant differences in economic resilience. Kunming, Lijiang, Diqing, and Dehong are above the average level of the province. Kunming is thriving. As the political, economic and cultural center of the province, Kunming has the strongest ability to withstand shocks when disturbed, and its economies is less affected by shocks. At the same time, the regional economy can be restored by appropriately adjusting the structure and functions of the regional economy.
Qujing, Yuxi and Honghe have been below the average level of the province. In general, the economic resilience of prefecture-level cities in Yunnan Province is highly polarized. Kunming's economic resilience is significantly higher than other cities, followed by Lijiang, Dehong and Diqing, and the remaining cities have relatively low economic resilience. The economic resilience of most cities is lower than the average value of Yunnan Province.



Fig. 4. Economic resilience of 16 cities in Yunnan Province from 2005 to 2017.

\section{CONCLUSION}

The concept of economic resilience is an important factor in explaining the regional differences in response to economic recession. However, most studies on economic resilience focus on the analysis of specific economic indicators and ignore the analysis of the capabilities behind these indicators. This paper constructs an analysis framework and indicator system for economic resilience based on social capabilities, and measures the economic resilience of 16 prefecture-level cities in Yunnan Province from 2005 to 2017. There are four main findings: First, the economic resilience of Yunnan Province has obvious time characteristics, 2006 and 2012 are two key time adjustment points. One is the adjustment and integration of resources within Yunnan Province, and the other one is Yunnan province with the help of the construction of the national bridgehead, Yunnan's economic resilience has been continuously improved, especially after the overlay of the Belt and Road Initiative. Second, the economic resilience of most cities in Yunnan Province is lower than the average level of Yunnan Province. This is mainly because these cities are relatively weak in resistance and recoverability. Third, the economic resilience of the 16 prefecture-level cities in Yunnan Province differs significantly. The provincial capital Kunming stands out with the highest economic resilience, followed by Lijiang, Dehong and Diqing, and the remaining cities have the weakest economic resilience. Fourth, the recoverability in economic resilience has always been higher than the resistance, indicating that the local government is actively exploring new development paths, which also lays the foundation for the subsequent improvement of economic resilience.

The current economic development of Yunnan Province has encountered major challenges from the international environment. The first is that the Sino-US trade conflict in 2019 has led to an increase in the trend of anti-globalization. The second is that the new crown pneumonia epidemic in 2020 has impacted the international and domestic industrial chains and supply chains. The two superimposed have brought shocks on the structure adjustments and economic development of Yunnan Province. However, there are opportunities in 
the crisis: on the one hand, the state has issued a series of support policies, on the other hand, Yunnan has also proposed a new infrastructure plan of 5 trillion yuan. Therefore, for all cities in Yunnan, the most urgent task is to seize opportunities, continuously improve social capabilities, and improve economic resilience to improve their ability to withstand shocks and accelerate economic transformation. Therefore, the first is to increase support for enterprises, encourage the development of private enterprises, realize the diversification of the economic system, support enterprise innovation through tax reductions and subsidies for scientific and technological funds, and continuously activate entrepreneurship. The second is to increase manpower training. On the one hand, it will increase support for local colleges and scientific research institutions, encourage school-enterprise cooperation, and integrate production and education. On the other hand, it will increase its attractiveness to talents in developed regions and absorb outstanding talents from the eastern and central regions talents to build Yunnan's local intellectual capital advantage. The third is to improve government governance. On the one hand, various policies are introduced to stimulate the economy and stabilize social confidence in the short term. On the other hand, the long-term plan is improved to break the limitations of the current development path of the region, adjust and transform its resources and structure. A good entrepreneurial environment and investment environment, optimizing the industrial structure, supporting the development of high-end service industries, transforming the economic development mode, forming a continuous impetus for the development of Yunnan, while improving various infrastructure construction, strengthening the connection of social networks, and enhancing social capital.

\section{References}

[1] Martin R. Regional economic resilience, hysteresis and recessionary shocks. Journal of Economic Geography, 2012, 12(1): 1-32.

[2] Reggiani A. Network resilience for transport security: some methodological considerations. Transport Policy, 2013, 28: 6368.

[3] Holling C S, 1973. Resilience and stability of ecological systems. Annual Review of Ecology and Systematics, 4: 1-23.

[4] Martin R, Sunley P, 2015. On the notion of regional economic resilience: conceptualization and explanation. Journal of Economic Geography, 15(1): 1-42.

[5] Boschma R, 2015. Towards an evolutionary perspective on regional resilience. Regional Studies, 49(5): 733-751.

[6] Carpenter S R, Westley F, Turner M G. Surrogates for resilience of social-ecological systems. Ecosystems, 2005, 8(8): 941-944.

[7] Simmie J, Martin R. The economic resilience of regions: towards an evolutionary approach. Cambridge Journal of Regions, Economy and Society, 2010, 3(1): 27-43.
[8] Hassink R. Regional resilience: a promising concept to explain differences in regional economic adaptability? Cambridge Journal of Regions, Economy and Society, 2010, 3(1): 45-58.

[9] Davoudi S, Brooks E, Mehmood A. Evolutionary resilience and strategies for climate adaptation. Planning Practice \& Research, 2013, 28(3): 307-322.

[10] Doran J, Fingleton B. Employment resilience in Europe and the 2008 economic crisis: insights from micro-level data. Regional Studies, 2016, 50(4): 644-656.

[11] Christopherson S, Michie J, Tyler P. Regional resilience: theoretical and empirical perspectives. Cambridge Journal of Regions, Economy and Society, 2010,3(1): 3-10.

[12] Louis Putterman. Institutions, social capability, and economic growth[J]. Economic Systems, 2013,37:345-353.

[13] Industrial development report 2005[R]. UNIDO

[14] $\mathrm{Hu}$ X H, Hassink R. Exploring adaptation and adaptability in uneven economic resilience: a tale of two Chinese mining regions. Cambridge

[15] Abramovitz, M. Catching up, forging ahead, and falling behind[J]. Journal of Economic History, 1986, 46:385-406.

[16] Bon Ho Koo, Dwight H. Perkins. Social Capability and LongTerm Economic Growth[M]. 1995. MACMILLAN PRESS LTD.

[17] Schumpeter, Joseph A. The Theory of Economics Development [M]. Cambridge MA, Harvard University Press, 1934

[18] Mazzola F, Lo Cascio I, Epifanio R et al. Territorial capital and growth over the Great Recession: a local analysis for Italy. The Annals of Regional Science, 2018, 60(2): 411-441.

[19] Angulo A M, Mur J, Trívez F J,. Measuring resilience to economic shocks: an application to Spain. The Annals of Regional Science, 2018, 60(2): 349-373.

[20] Smith, R., Simard, C. \& Sharpe, A. A Proposed Approach to Environment and Sustainable Development Indicators Based on Capital. The National Round Table on the Environment and the Economy's Environment and Sustainable Development Indicators Initiative, 2001.

[21] Sagan I, Masik G,. Economic resilience. The case study of Pomorskie region. Raumforschung und Raumordnung, 2014,72(2):153-164.

[22] Green, G.P. \& Haines, A. Asset building and community development. Thousand Oaks, CA: Sage,2002.

[23] Putnam, R. D. Tuning In, Tuning Out: The Strange Disappearance of Social Capital in America. Political Science and Politics, 1995, 28(4), 664-683.

[24] Di Caro P, 2017. Testing and explaining economic resilience with an application to Italian regions. Papers in Regional Science, 96(1): 93-113.

[25] Giannakis E, Bruggeman A. Determinants of regional resilience to economic crisis: a European perspective. European Planning Studies, 2017, 25(8): 1394-1415.

[26] Joseph S. Mayunga. Understanding and Applying the Concept of Community Disaster Resilience: A capital-based approach. A draft working paper prepared for the summer academy for socia vulnerability and resilience building, 22 - 28 July 2007, Munich, Germany.

[27] Tan Juntao, Zhang Pingyu, LO Kevin, LI Jing, LIU Shiwei Conceptualizing and Measuring Economic Resilience of Resource-based Cities: Case Study of Northeast China. Chinese Geographical Science, 2017, 27(3): 471-481.

[28] Li Liangang, Zhang Pingyu, LO Kevin, LIU Wenxin, LI Jing. The Evolution of Regional Economic Resilience in the Old Industrial Bases in China: A Case Study of Liaoning Province, China. Chinese Geographical Science. 2019. 